Iran Journal of Nursing (IJN)

Vol 34, No. 131, Aug 2021: 7- 18

\title{
Predicting Exclusive Breastfeeding Based on Maternal Personality Traits: A Correlational Study
}

\author{
Fatemeh Padashian $^{1}$, Parvin Yadollahi $^{2}$, Zeinab Moshfeghy ${ }^{3}$
}

\begin{abstract}
Background \& Aims: World Health Organization (WHO) greatly recommends exclusive breastfeeding as the perfect nutrition for infant feeding. Breastfeeding is associated with short -term and long- term advantages for maternal and child health. Short term advantages in children include reduction of diarrhea and pneumonia. And the long- term advantages of breastfeeding include reduced risk of obesity and chronic diseases such as type I \& II diabetes, hypertension, heart diseases, and hyperlipidemia in adulthood and improved cognitive functions. Breastfeeding advantages for mothers include more mother-infant bonding and reduced risk of breast cancer, ovarian cancer, and type II diabetes. Many studies have documented the relationship between healthy behaviors and personality traits, so it seems that breastfeeding is related to such traits. So, this study aimed to investigate predicting exclusive breastfeeding based on maternal personality traits.

Material \& Methods: A descriptive-predictive study was used to achieve the research purpose. The study followed random cluster sampling method. For this purpose, first Valfajr and Enghelab Centers were selected as clusters, and three comprehensive health care centers were selected randomly from these clusters. Finally, 120 eligible mothers referring to 6 comprehensive health centers of Shiraz participated in this study. In order to determine the sample size, the rule of sixty in the structural equation prediction model was employed. According to this law, 10 samples were selected for each parameter. Data were collected between May to December 2019. The inclusion criteria were willingness to participate in the study, Iranian mothers with an infant aged 6-12 months and the experience of exclusive breastfeeding, singleton pregnancy, lack of any breast disorders, normal vaginal delivery, not using any lactation-inducing medications, not having any medical complications, not having been hospitalized for any reasons, not using any psychiatric medications during the breastfeeding period, and term pregnancy. The exclusion criteria were incomplete questionnaires. Data were gathered using a demographic questionnaire which included items relating to maternal and child age, education level of couples, income, occupation, breastfeeding education during pregnancy and after childbirth, emotional support during the breastfeeding period on the part of the husband or family, and delivery type. The other instruments included Exclusive Breastfeeding Scale with 23 items on attitude, abstract norms, perceived behavior control, and behavioral intention; and the shortened scale of Big Five Factors (BFF) about Personality Traits which included 21 items relating to extraversion, neuroticism, openness to experience, task-orientation, and agreeableness. The researcher selected the samples who met inclusion criteria; and then, she introduced herself to them and explained the research objectives. The participants were also ensured about the confidentiality of the data. A written consent form was obtained from anyone who agreed to participate in the study. Afterwards, the questionnaires were completed in the presence of the researchers. Descriptive statistical methods (mean, standard deviation, and Pearson correlation coefficient) were used to analyze the data. In order to predict exclusive breastfeeding based on personality traits, multiple linear regression through Enter method was used in SPSS 16. Before the multiple regression analysis, the presumption of multicollinearity and normality effects of the data were evaluated, which
\end{abstract}

\footnotetext{
1. Midwifery Department, School of Nursing and Midwifery, Shiraz University of Medical Sciences, Shiraz, Iran 2. Midwifery Department, Maternal-Fetal Medicine Research Center, Shiraz University of Medical Sciences, Shiraz, Iran (Corresponding Author) Tel: $09173025984 \quad$ Emali:p_yadolahi@sums.ac.ir

3. Midwifery Department, Community Based Psychiatric Care Center, Shiraz University of Medical Sciences, Shiraz, Iran
} 
indicated the normal distribution of the variables and there were no outliers in data. The variance inflation factor (VIF) index was accounted to be less than 1.5. The $\mathrm{P}$-value was set at 0.5 for all tests.

Results: The participants aged 17-45 years $((M=31.04, S D=5.12)$. The infants aged 6-12 months $(M=9.56$, $\mathrm{SD}=2.41$ ). In this study $88.3 \%$ of the participants were housewives. Almost half of them had a Bachelor's degree and above (48.3\%) and their spouses had diplomas (45.8\%). The majority of the participants $(91.7 \%)$ were emotionally supported and encouraged to breastfeed by their spouses and $95 \%$ by their families. Also, the majority of subjects (89.2\%) received breastfeeding training during pregnancy and $95.8 \%$ of them received the training during the postpartum period. The table of mean scores of personality traits showed that individuals with agreeableness showed the highest mean score $(16.13, \mathrm{SD}=2.16)$ and individuals with neuroticism characteristics showed the lowest mean score $(12.13, \mathrm{SD}=2.68)$. The results of the Pearson correlation coefficient showed that among the personality traits, the extraversion component had a meaningfully positive relationship with exclusive breastfeeding $(\mathrm{r}=. / 36, \mathrm{p}=0.024)$. The results of linear multiple regression analysis showed that the predictor variables were the extraversion $(\mathrm{P}=0.0001, \beta=0.43)$ and task- orientation $(\mathrm{P}=0.048, \beta=0.18)$. These variables explained $21 \%$ of total variance. All other variables were not meaningful.

Conclusion: It can be concluded that extraversion and task- orientation predicted exclusive breastfeeding positively. Given that personality traits are relatively stable, the relationship between extraversion and taskorientation with exclusive breastfeeding has beneficial outcomes for maternal and child health. Positive emotion is one of the features of extravert people and competency is the feature of task- oriented people. If it is possible to provide situations for mothers to experience more positive excitement or to feel more adequacy and competence, breastfeeding quality will be improved. For this purpose, it is necessary to teach the discipline in breastfeeding, tell the mothers to have a happy life, and tell them about mother- infant intimacy. It is hoped that presenting the results of this study to health care providers leads to more encouragement and support for women in the field of exclusive breastfeeding and the provision of safe breastfeeding counseling in health centers. One of the limitations of the present study was inadequate access to eligible mothers participating in the study due to the restricted time of the researcher in collecting data and reduced mother' desire to exclusive breastfeeding, which can be effective in the lack of significant relationship between other components of personality traits and exclusive breastfeeding. The strength of this study was that it was one of the few studies conducted in Iran which investigated the relationship between two essential and vital variables, i.e. personality traits and exclusive breastfeeding in analyzing the mother and infants' health. Future researches should examine the role of mediator variables in the relationship between these personality traits and exclusive breastfeeding and effect of socio-cultural and economic factors on exclusive breastfeeding. Finally, designing qualitative study to determine other barriers to exclusive breastfeeding is recommended.

Key words: Breastfeeding, Exclusive, Personality Traits

\section{Conflict of Interest: No}

How to Cite: Padashian F, Yadollahi P, Moshfeghy Z. Predicting Exclusive Breastfeeding Based on Maternal Personality Traits: A Correlational Study. Iran Journal of Nursing. 2021; 34(131):7-18.

Received: 3 May 2021

Accepted: 4 Aug 2021 


\title{
يش بينى شيردهى انحصارى بر اساس ويزگىهاى شخصيتى مادر: يك مطالعه همبستىى
}

\author{
فاطمه پِاداشيان '، يروين يدالهى '، زينب مشفقى
}

جكيده

زمينه و هدف: سازمان بهداشت جهانى، همواره شيردهى انحصارى را به عنوان بهترين منبع تغذيه شيرخوار بيشنهاد مى كند. نظر به اهميت اين رويداد

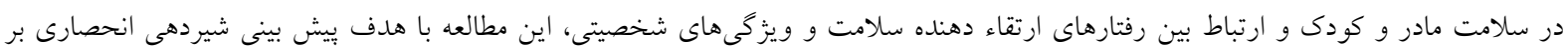
اساس ويزگكى هاى شخصيتى مادر انجام شد.

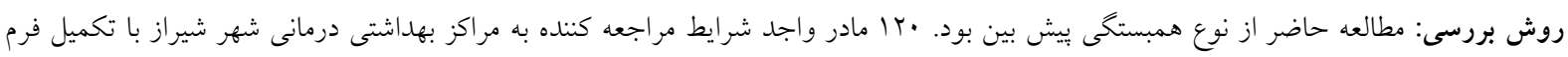

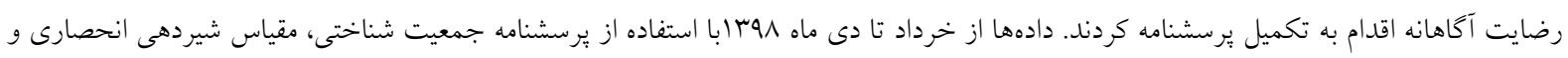

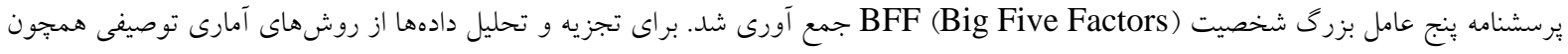

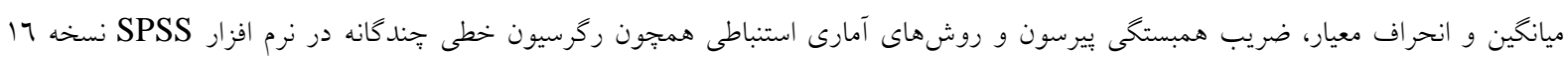

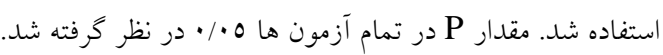

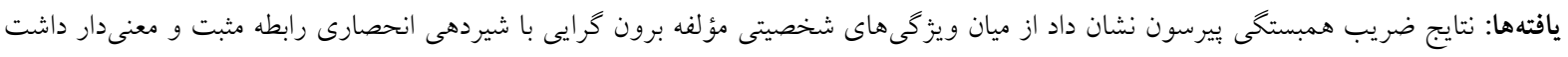

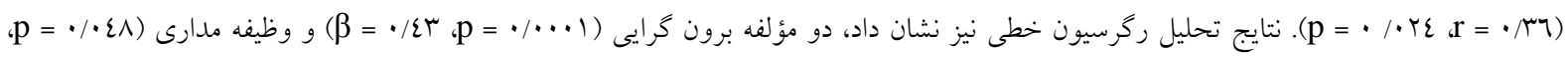

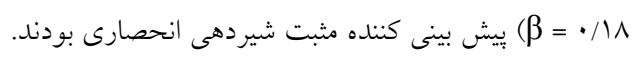

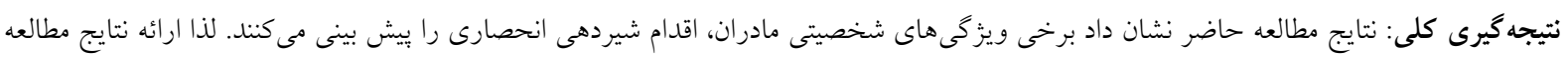

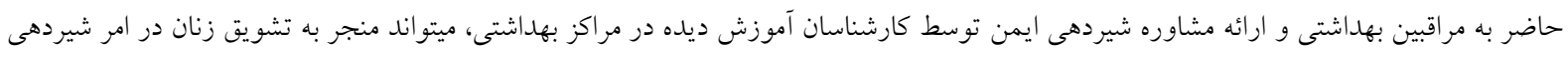

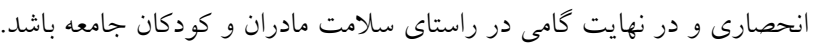

كليد وازهها: شيردهى، شيردهى انحصارى، ويزّىى هاى شخصيت

$$
\text { تعارض منافع: ندارد }
$$

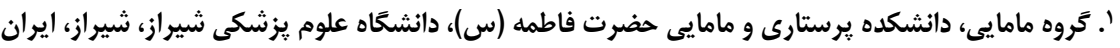

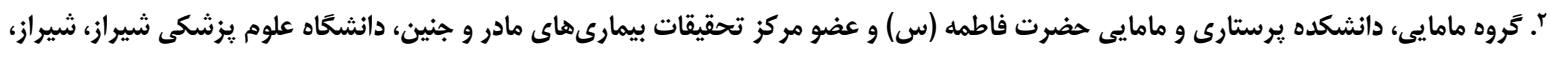
Email: pyadolahi @sums.ac.ir

شماره تماس:

ايران

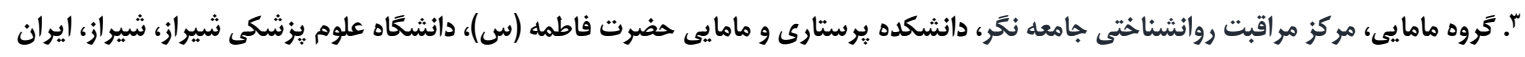


رعايت مى كنند (rا). اين ميزان در يك مطالعه ملى در ايران

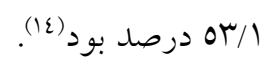

شيردهى بديدهاى بيجِيده است و شروع و ادامه آن تحت

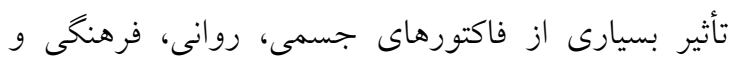

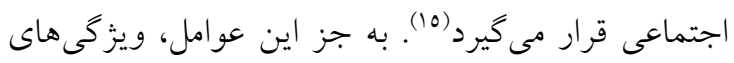

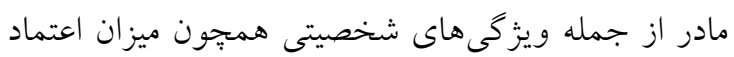

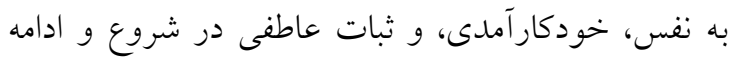

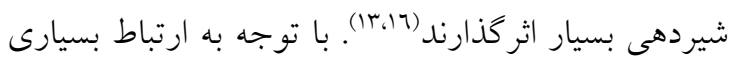

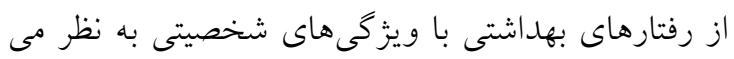

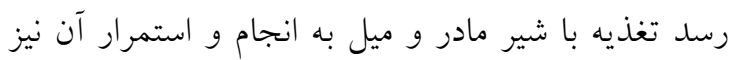

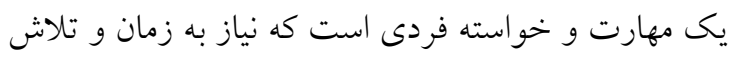
براى كسب آن دارد و با برخى ويزگكى هاى شخصيتى مادر

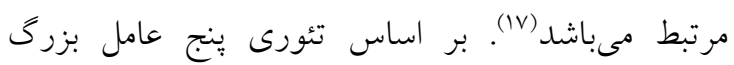

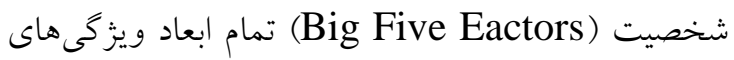

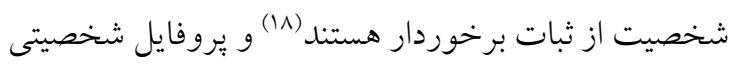

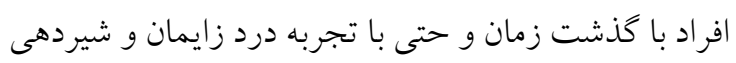

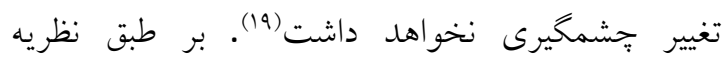
McCrae and Costa است كه شامل روان نزندكرايى يا Neuroticism (افراد

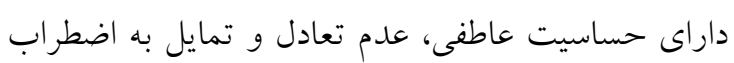

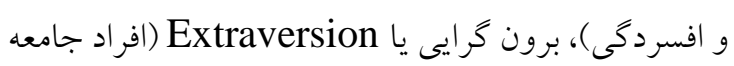

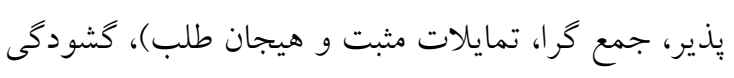
در تجربه يا Openness experience (افراد كنجكاو،

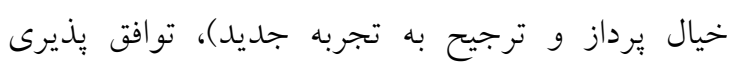
Agreeableness

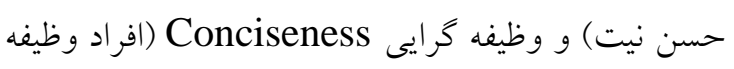

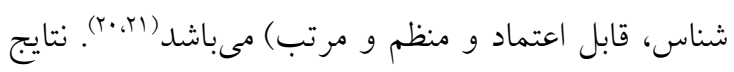

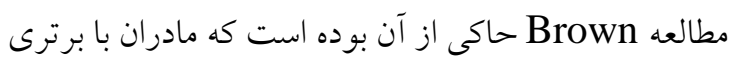

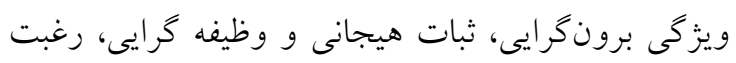

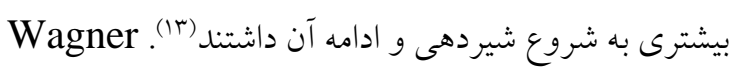

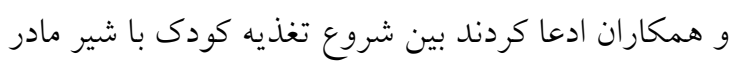

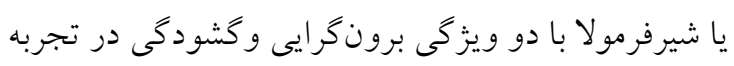

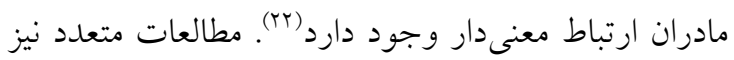

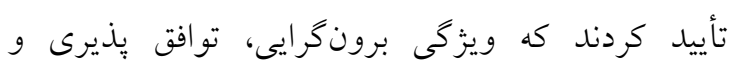

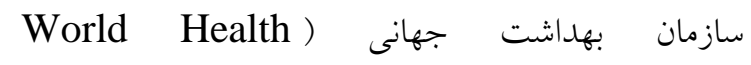

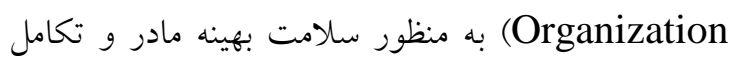
مطلوب نوزاد همواره شيردهى انحصارى را به صورت

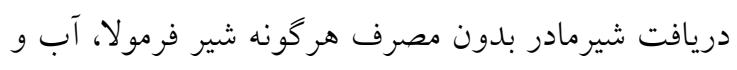
آبميوه به مدت شش ماه توسط شيرخوار توصيه مى كند (1).

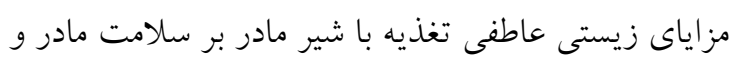

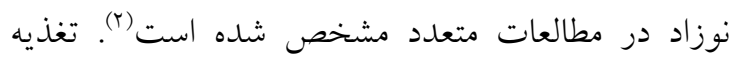
انحصارى با شير مادر مزاياى كوتاه مدتى همجيون افزايش دلبستكى و وبيوند مادر- كودى، كاهش ابتلا به اسهال،

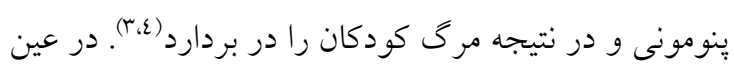

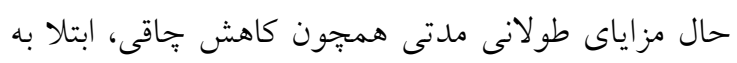

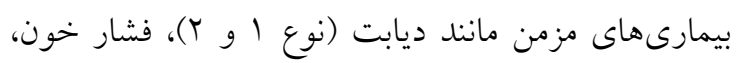

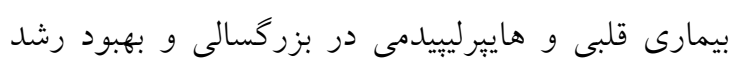

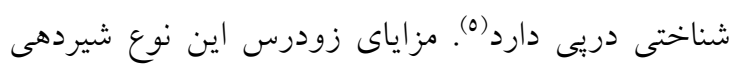

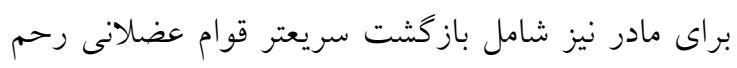

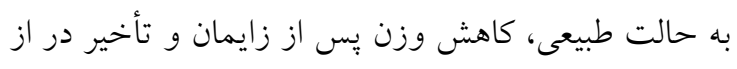

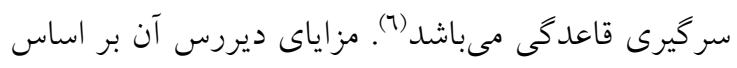

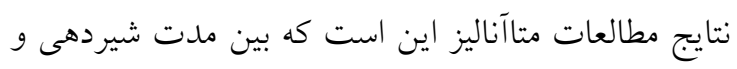
خطر ابتلاى مادر به ديابت نوع r، سرطان يستان و و تخمدان رابطهاى معكوس وجود دارد (V-9).

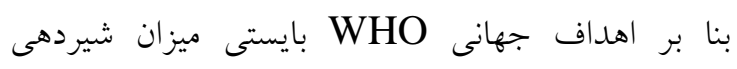

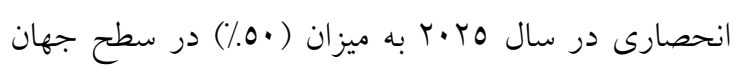

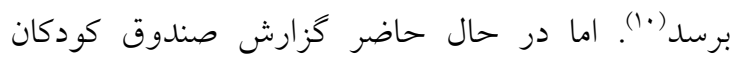
سازمان ملل متحد (UNICEF) حاكى از ميزان كم شيردهى و شيوههاى تغذيه تكميلى ضعيف در سطح جهان

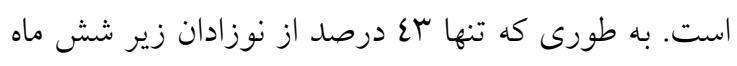
به طور انحصارى با شير مادر تغذيه مى شوند (1"). اين ميزان

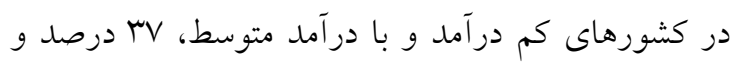

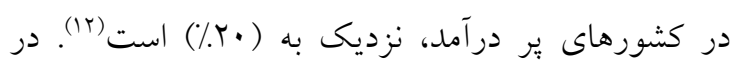

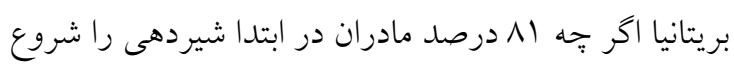
مى كنند، يس از شش هفته اين ميزان به میع درصد رسيده

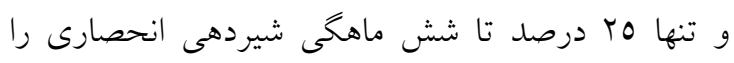


در شكل مطلوبتر •† آزمودنى مورد نياز است(YV). با توجه

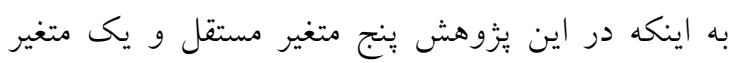

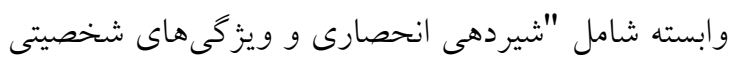

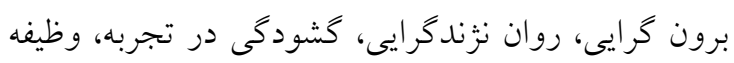

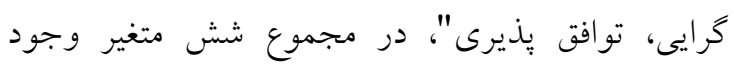

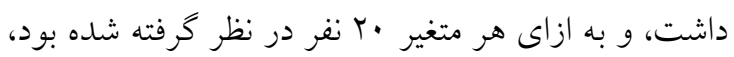

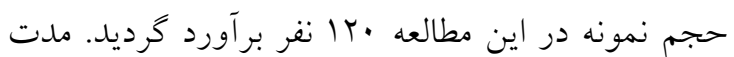

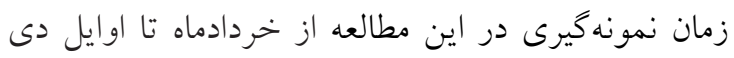
ماه يرجا به طول انجاميد. معيار ورود به مطالعه عبارت بودند از مادران داراى شير خوار 7 تا با ماه و سابقه شيردهى انحصارى، حاملكى تك قلو، فقدان هر گونه مورد

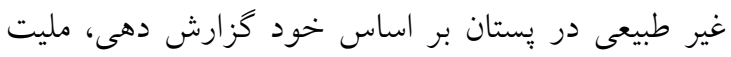

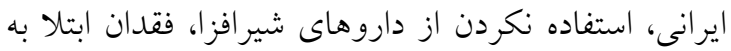

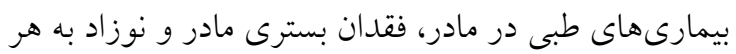

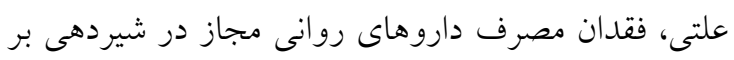

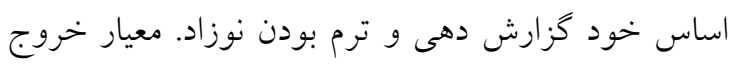

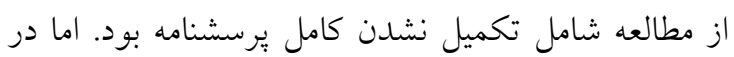

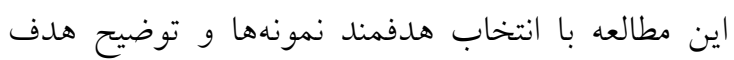

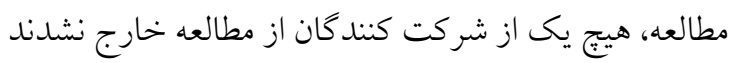

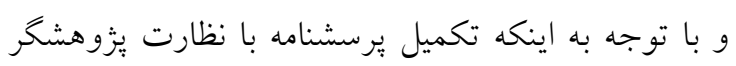

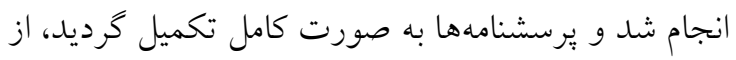

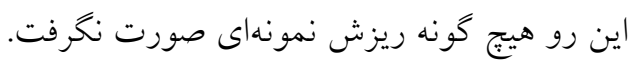
يزوهشخر بس از دريافت مجوز از كميته اخلاق دانشخاه

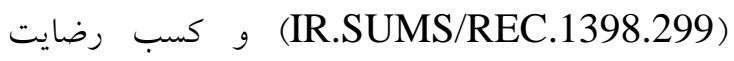

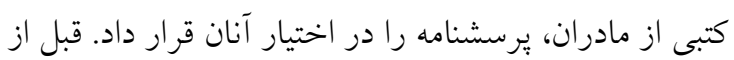

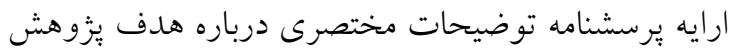

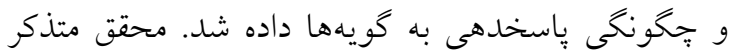
شد كه نيازى به بيان نام و مشخصات نيست. به منظور

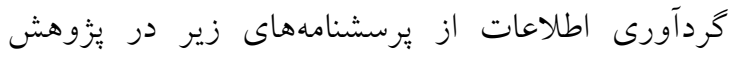
استفاده شد: يرسشنامه دموكرافيك كه شامل اطلاعات بارورى و جمعيت شناختى و شامل سن مادر و كودى، سطح تحصيلات مادر و همسر، درآمد، اشتغال، دريافت آموزش شيردهى در دوران بارداى و يّ از زايمان، حمايت

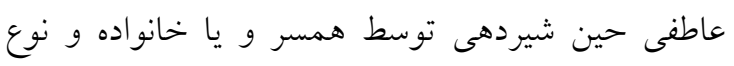

گشودگى در تجربه بر شروع و ادامه شيردهى تأثير مثبت

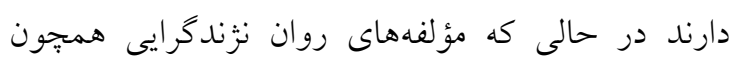

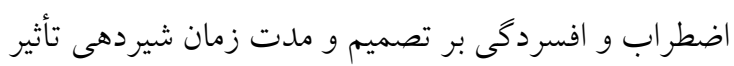
منفى داشت (Tr-rT). با وجود تأكيد سازمان بهداشت جهانى بر مزاياى تغذيه

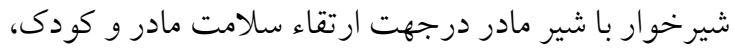
همواره شاهد كاهش شيردهى انحصارى توسط مادران

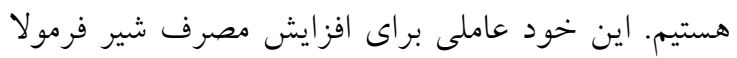
مىباشد كه علاوه بر افزايش بار اقتصادى براى خانواده و كشور، سبب كاهش دلبستى بين مادر و كودى و ساير عوارض جسمى و شناختى رفتارى به ويزه در شيرخوار مىشود. عوامل متعدد از جمله صفات شخصيتى مى تواند

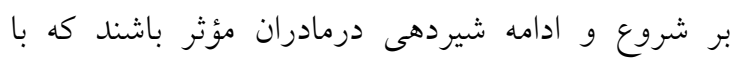

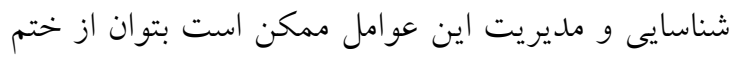
زودرس شيردهى و بيامدهاى منفى آن بيشكيرى كرد. از

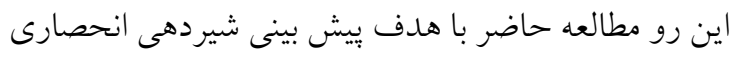
بر اساس ويزگى هاى شخصيتى مادر انجام گرفت. اميد

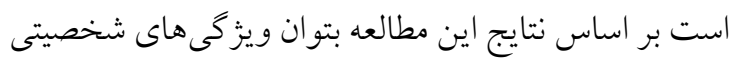

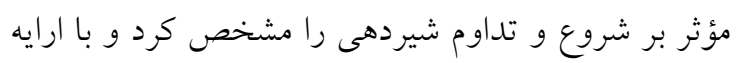

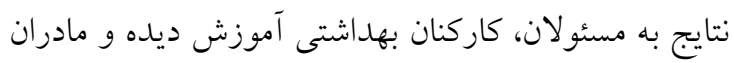
كامى در جهت ارتقاى سلامت مادر و كودى برداشت.

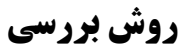
اين يك مطالعه مقطعى از نوع همبستخى بيش بيش بين بود. به

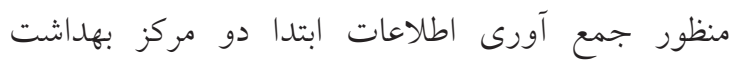

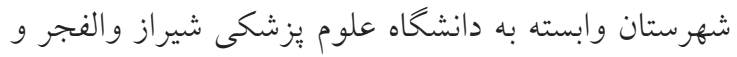
انقلاب به عنوان خوشهها در نظر كرفته شدند. سبس از هر خوشه به تصادف سه مركز جامع سلامت انتخاب شدند. بدين ترتيب در مجموع شش مركز جامع سلامت، محيط يُزوهش را تشكيل دادند. جامعه يُزوهش كه در بركيرنده مادران داراى شيردهى انحصارى بود، به صورت مستمر مورد مطالعه قرار كرفتند. به منظور تعيين حجم نمونه از قانون شصت موجود در مدل بيش بينى ركرسيونى استفاده

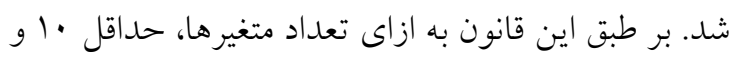


كويه بود و با مؤلفههاى برون گرايى (با كويههاى

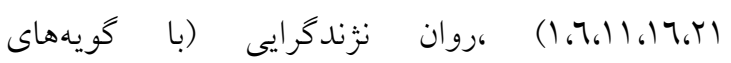

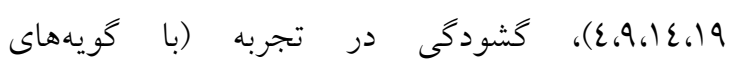

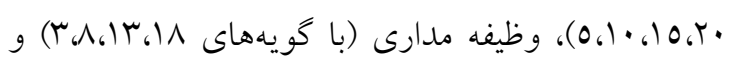

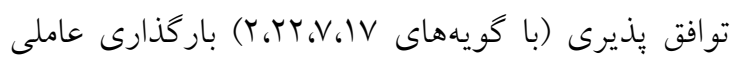

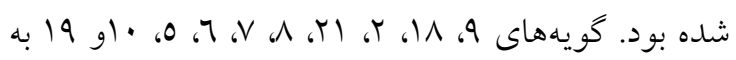
صورت معكوس نمره كذارى شدند. نتيجه تحليل عاملى

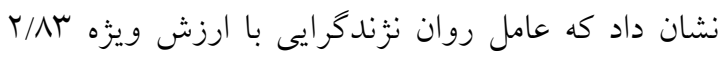

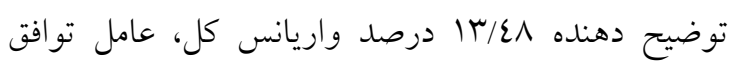

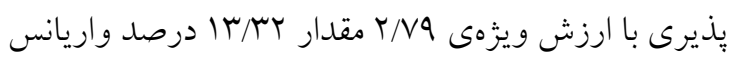

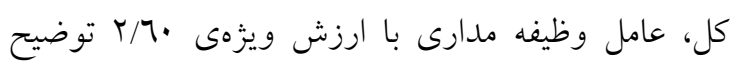
دهندهى

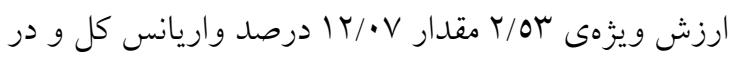

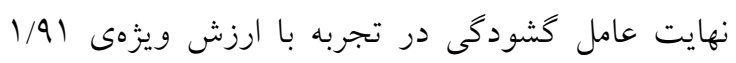

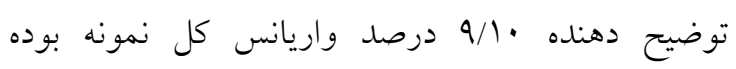
است (ra)

يرسشنامها توسط شركت كنند كان و درحضور يزوهشكر

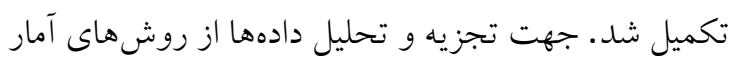

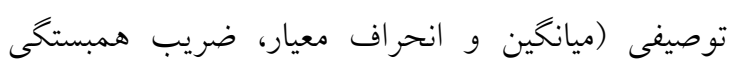

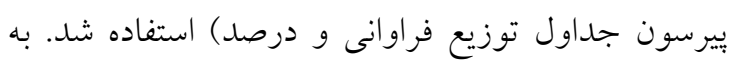
منظور بيش بينى شيردهى انحصارى بر اساس ويز كى هاى

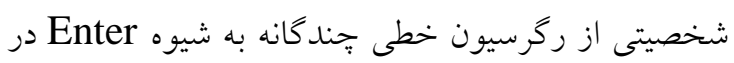

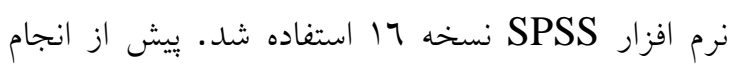

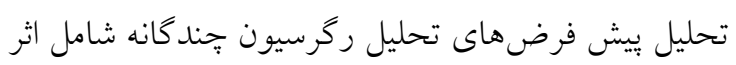

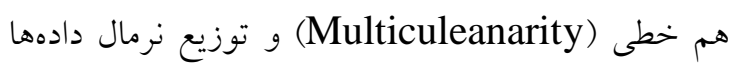
مورد ارزيابى قرار گرفت كه نشان دهنده توزيع نرمال متغير

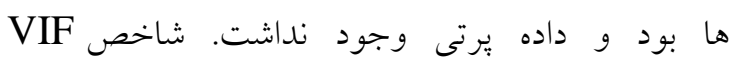
كمتر از (variance inflation Factor)

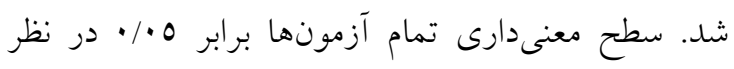

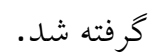

\section{يافتهها}

با نظارت محقق، تمامى شركت كنند أنان به كل كويههاى

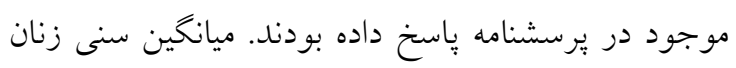

زايمان بود. يرسشنامه شيردهى انحصارى ( Exclusive

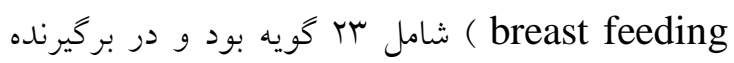
نحرش (در قالب لا كويه)، هنجارهاى انتزاعى (در قالب

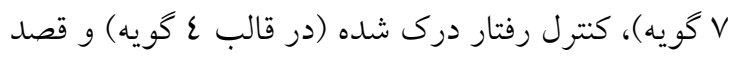

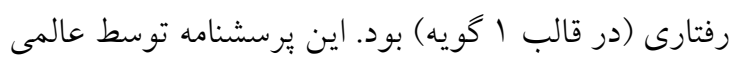

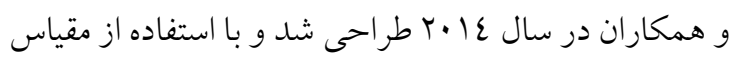
ه درجهاى ليكرت سنجش شد. در صورت توافق كامل

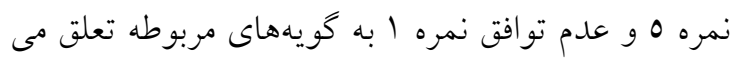

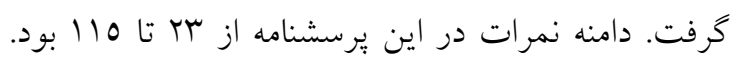
بدين ترتيب كسب نمره بالاتر به معنى داشتن تمايل بيشتر

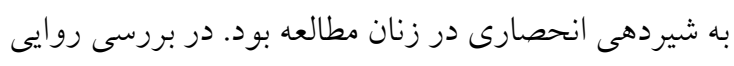

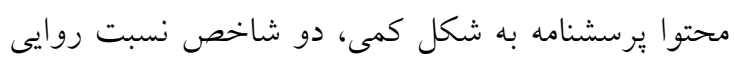

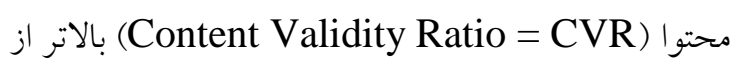

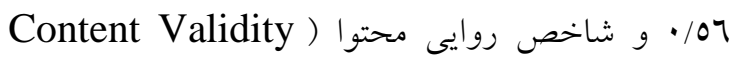
(Index=CVI

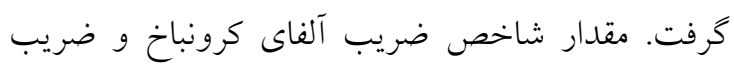
همبستخى درون خوشهاى ( Intra-class Correlation (Coefficient = ICC كزارش شده بود (「^). يرسشنامه سوم، برسشنامه كوتاه شده

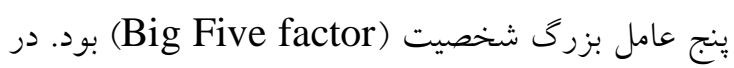
اين يرسشنامه نيز گويهها بر اساس مقياس ليكرت امتئ امتياز

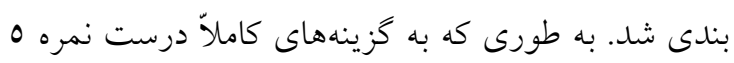

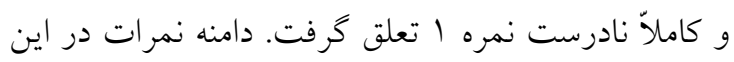

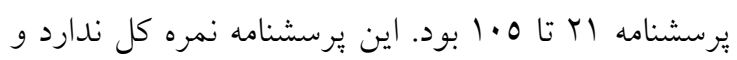

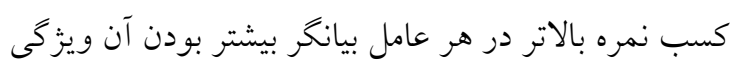
در فرد است روايى و يايايى آن توسط خرمايى و همكاران

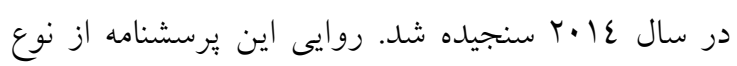

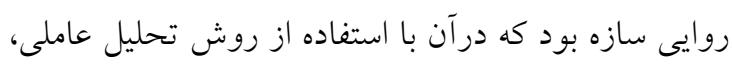

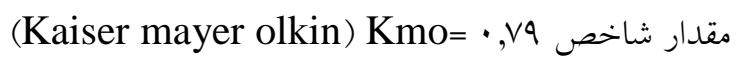

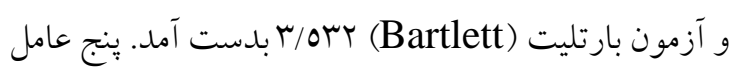
در مجموع رش/ •7 از واريانس كل را توضيح دادهاند. اين

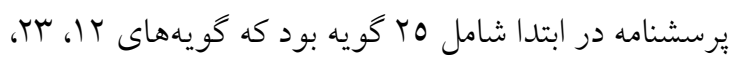

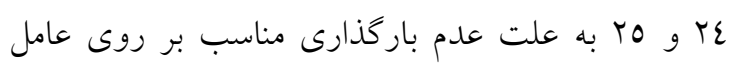

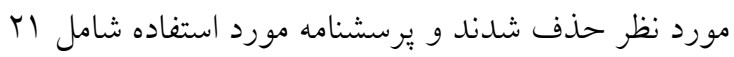


شركت كنند كان توسط همسر و (90\%)توسط خانو اده مورد شركت كننده در مطالعه r/ I/ حمايت عاطفى و تشويق به شيردهى قرار گرفته بودند.

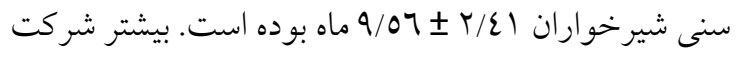

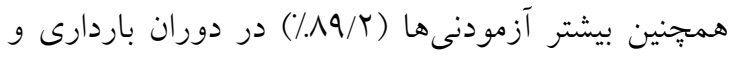

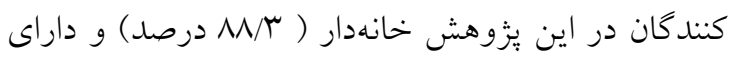

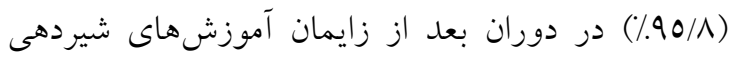

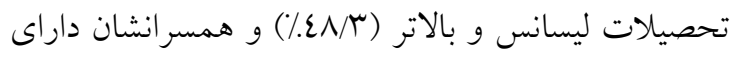
دريافت كرده بودند (جدول شماره ()).

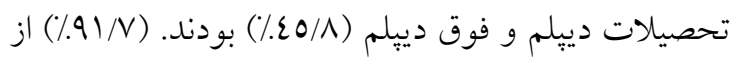

جدول شماره ا: فراوانى و ميانكَين متغيرهاى جمعيت شناختى مادران داراى شيردهى انحصارى مراجعه كننده به مراكز بهداشتى شيراز

\begin{tabular}{|c|c|c|c|c|}
\hline \multicolumn{2}{|c|}{ شيردهى انحصارى } & \multirow{2}{*}{$\begin{array}{l}\text { Sل نمونه } \\
\text { S-Ir. }\end{array}$} & \multirow[t]{2}{*}{ رده بندى } & \multirow[t]{2}{*}{ متغيرهاى توصيفى } \\
\hline نتيجه آزمون & ضريب همبستخى & & & \\
\hline $\mathrm{P}=\cdot / \wedge 0$ & $r=\cdot / \cdot r$ & $r / / \cdot \varepsilon \pm 0 / 1 r$ & ل IV & سن مادر (Mean \pm (SD) \\
\hline $\mathrm{P}=\cdot / \mathrm{rr}$ & $\mathrm{r}=\cdot / 11$ & $9 / 07 \pm r / 21$ & T & سن شيرخوار (Mean (M SD) \\
\hline \multirow[t]{4}{*}{$\mathrm{P}=\cdot / 14$} & $r=-\cdot / 1 r$ & $10(\% 1 r / 0)$ & كم تر از يك & \\
\hline & & or $(/ . \varepsilon \varepsilon / r)$ & $1-r$ & درآمد ماهيانه، ميليون (فراوانى.) \\
\hline & & 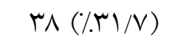 & $r-7$ & \\
\hline & & $1 \varepsilon(/ 11 / \mathrm{V})$ & بالاتر از 7 & \\
\hline \multirow[t]{4}{*}{$\mathrm{P}=\cdot / \mathrm{rr}$} & $r=\cdot / 11$ & $r(/ / r / 0)$ & ابتدايى & \\
\hline & & $1 \varepsilon(\% 11 / \mathrm{V})$ & سوم راهنمايى & تحصيلات مادر (فراوانى.) \\
\hline & & $\varepsilon 0(/ . r V / 0)$ & دييلم و فوق دييلم & \\
\hline & & $0 \wedge(/ . \varepsilon \wedge / \Gamma)$ & ليسانس و بالاتر & \\
\hline \multirow[t]{4}{*}{$\mathrm{P}=\cdot / 94$} & $\mathrm{r}=\cdot / \cdot \bullet$ & $0(/ / \varepsilon / T)$ & ابتدايى & \\
\hline & & $\operatorname{lr}(\% / 1 \cdot /)$ & سوم راهنمايى & تحصيلات همسر (فراوانى.) \\
\hline & & $00(\% 20 / 1)$ & دييلم و فوق دييلم & \\
\hline & & $\varepsilon V(/ / r q / \Gamma)$ & ل ليسانس و بالاتر & \\
\hline \multirow[t]{2}{*}{$\mathrm{P}=\cdot / q \varepsilon$} & $\mathrm{r}=. / \cdot 7$ & $9 \wedge(/ / \Lambda) / N)$ & بله & باردارى برنامه ريزى شده (فراوانى ٪) \\
\hline & & $r(\% / N / r)$ & خير & \\
\hline \multirow[t]{2}{*}{$\mathrm{P}=\cdot / \varepsilon 0$} & $r=. / \cdot r$ & $1 \cdot V(/ / \wedge 9 / r)$ & بله & دريافت آموزش شيردهى در دوران \\
\hline & & $\operatorname{lr}(\% \cdot / / \Lambda)$ & خير & باردارى (فراوانى٪) \\
\hline \multirow[t]{2}{*}{$\mathrm{P}=\cdot / \mathrm{u}$} & $\mathrm{r}=-\cdot / \cdot \varepsilon$ & $11 \cdot(1.91 / \mathrm{N})$ & بله & حمايت بدر در زمان شيردهى \\
\hline & & $1 \cdot(/ . \wedge \mu)$ & خير & 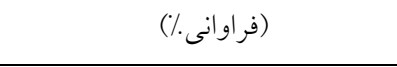 \\
\hline \multirow[t]{2}{*}{$\mathrm{P}=\cdot / \mathrm{OV}$} & $r=-\cdot / \cdot \wedge$ & $11 \varepsilon(1.90)$ & بله & حمايت خانواده در زمان شيردهى \\
\hline & & $7(\% .0)$ & 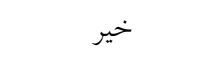 & 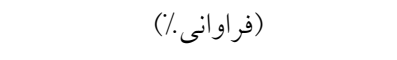 \\
\hline
\end{tabular}

SD: standard deviation

نتايج ضريب همبستخى ييرسون نشان داد كه از بين ويزگكى

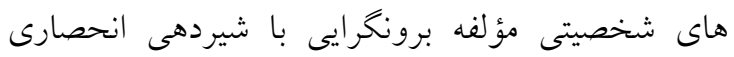

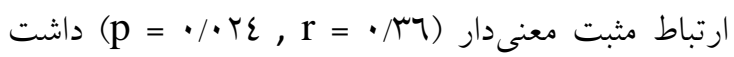

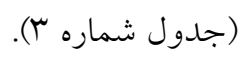

ميانخين نمره شيردهى انحصارى و نمرات ويزگكىهاى

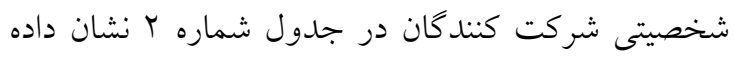

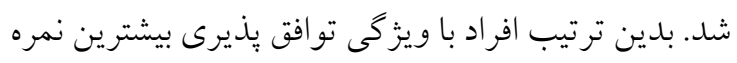

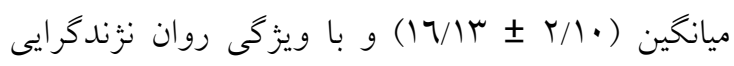

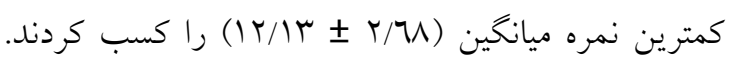




\begin{tabular}{|c|c|c|c|c|c|}
\hline Mean \pm SD & بيشينه & كمينه & تعداد & متغير & \\
\hline $\mid r / M \Psi T / T \Lambda$ & $r$. & $\mathrm{v}$ & Ir. & روان نزندكر ايى & \\
\hline $\mid \tau / 1 T \pm r / 1$ & r. & 1. & ir. & توافق بذيرى & \\
\hline $10 / 17 \pm 1 / 97$ & r. & 1. & ir. & وظيفه كرايى & ويزّكى هاى شخصيتى \\
\hline$|r / 77 \pm r /| \varepsilon$ & iv & $\wedge$ & ir. & برون كرايى & \\
\hline $\mid r / q V \pm r / T V$ & $r$. & 9 & ir. & كُشودگى به تجربه & \\
\hline$\varepsilon r / \Gamma \wedge \pm T / \wedge$ & or & rV & kr. & ن نكرش & \\
\hline$r \cdot / 7 \cdot \pm r / \mu r$ & ro & r & ir. & هنجارهاى انتزاعى & \\
\hline $1 r / 7 \varepsilon \pm r / \wedge q$ & 19 & 7 & ir. & كنترل رفتار درك شده & شيردهى انحصارى \\
\hline$\varepsilon / \varepsilon 9 \pm / / \mathcal{M}$ & 0 & 1 & ir. & قصد رفتارى & \\
\hline $91 / 1 r \pm 11 / 9 r$ & 1.9 & TV & Ir. & شيردهى انحصارى & \\
\hline
\end{tabular}

SD: standard deviation

جدول شماره سّ: نتايج ضريب همبستكى ييرسون در خصوص رابطه ويزتى هاى شخصيتى و شيردهى انحصارى در مادران مراجعه كننده به مراكز بهداشتى شيراز

\begin{tabular}{|c|c|c|c|c|c|}
\hline كثودگى به تجربه & توافق بذيرى & وظيفه گرايى & برون كرايى & رواننزند گرايى & متغير \\
\hline$r=\cdot / \cdots \wedge$ & $\mathrm{r}=-\cdot / \mathrm{r}$ & $r=\cdot / / r$ & $\mathrm{r}=\cdot / \mathrm{r}^{* *}$ & $\mathrm{r}=-\cdot / 11$ & شيردهى انحصارى \\
\hline $\mathrm{p}=\cdot / 9 r$ & $\mathrm{p}=\cdot / / \wedge$ & $\mathrm{p}=\cdot / / \varepsilon$ & $\mathrm{p}<\cdot / \cdot \cdot 1$ & $\mathrm{p}=\cdot / r r$ & \\
\hline
\end{tabular}

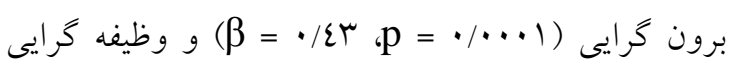
) بيشبينى كننده مثبت شيردهى

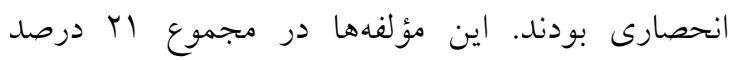
واريانس كل شيردهى انحصارى را تبيين نمودند (جدول شماره ع).
در مطالعه حاضر بر اساس تحليلهاى صورت گرفته رابطه

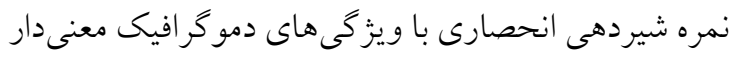
نشده است (جدول شماره (). يافتهاى تحليل رخرسيون

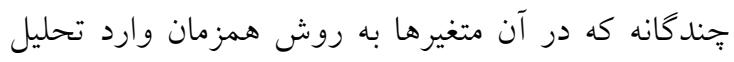

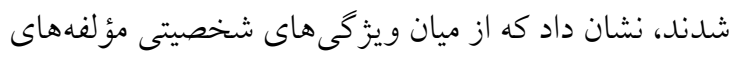

جدول شماره ع: نتايج تحليل رتر سيون קندكانه براى بيش بينى شيردهى انحصارى بر اساس ويزتىهاى شخصيتى مادران مراجعه كننده

\begin{tabular}{|c|c|c|c|c|c|c|c|c|}
\hline \multirow{3}{*}{$\mathbf{R}^{2}$} & \multirow{3}{*}{$\mathbf{R}$} & \multirow{3}{*}{ VIF } & & & & & & به مراكز بهداشتى ؛ \\
\hline & & & \multicolumn{2}{|c|}{ CI\%9D } & \multirow[t]{2}{*}{$\mathbf{P}$} & \multirow[t]{2}{*}{$T$} & \multirow{2}{*}{ ضريب استاندارد } & \multirow[t]{2}{*}{ متغيرها } \\
\hline & & & بالاترين & يايين ترين & & & & \\
\hline \multirow[t]{5}{*}{$\cdot|r|$} & $\cdot / \varepsilon 7$. & $1 / 1 \varepsilon$ & $r / O V$ & $1 / \cdot 7$ &.$/ \cdot 1$ & $\varepsilon / N \wedge$ & $\cdot / \varepsilon r$ & برون كرايى \\
\hline & & $1 / 1 T$ & $r / I r$ & $\cdot / \cdot 1$ &.$/ .0$ & r &.$/ 1 \Lambda$ & وظيفه گرايى \\
\hline & & $1 / .0$ & $\cdot / \varepsilon r$ & $-1 / \cdot 1$ & $\cdot / \mu \Lambda$ & $-\cdot / A V$ & $-\cdot / \cdot v$ & رواننزند گرايى \\
\hline & & $1 / \cdot 1$ &.$/ .70$ & $-1 / M \Lambda$ & $\cdot / \cdot 7$ & $-1 / 10$ &.$- / 17$ & توافق يذيرى \\
\hline & & $1 / T r$ & $\cdot / r 7$ & $-1 / 77$ &.$/ 10$ & $1 / \varepsilon \varepsilon$ & . & كشودگى به تجربه \\
\hline
\end{tabular}


كار توان بيشترى نشان مىدهند. همجنين زندكى برتحرى

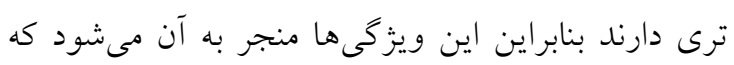

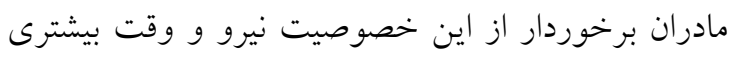
را براى شيردهى كودى صرف كنند و فعالانه در تغذيه كودى اقدام ورزند. هيجان خواهى و هيجانهاى مثبت هوده

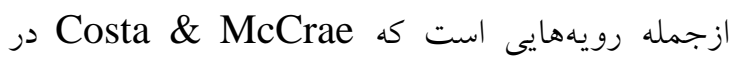
صفت برون گرايى قرار مىدهند. افراد برخوردار از اين رهن رويهها هيجان خواه و محرى طلب هستند. اين افراد

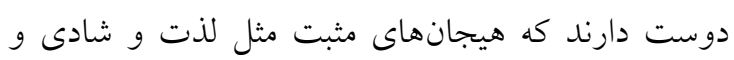

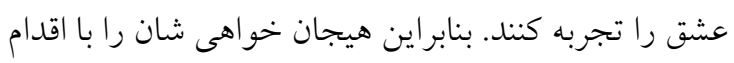
به شيردهى نشان مى دهند (•r). Verbeek و همكارانش

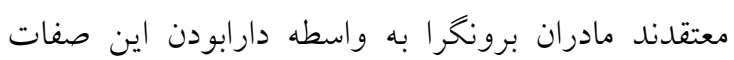
درونى و با جستجوى اطلاعات تخصصى، به افزايش

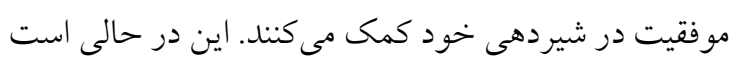

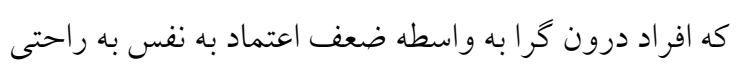
تحت فشار ديخران شيردهى را متوقف مى كنند (عَ). نتيجه ديخر مطالعه حاضرحاكى از آن بود كه ويزگ في وظيفه

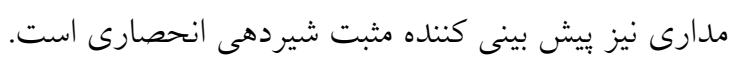

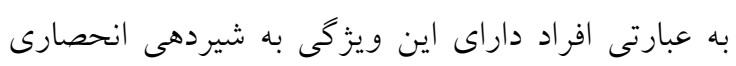

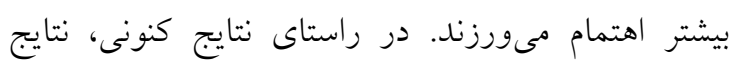
مطالعه Brown و همكاران نشان داد كه مادران وظيفه مدار

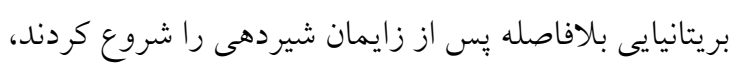

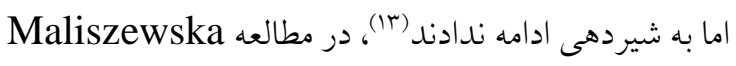

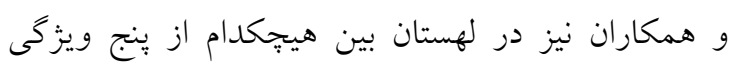

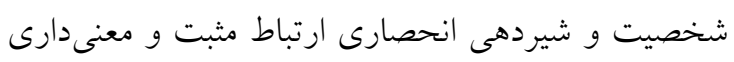

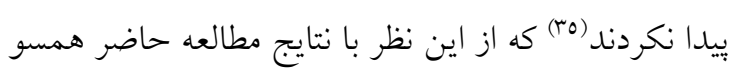

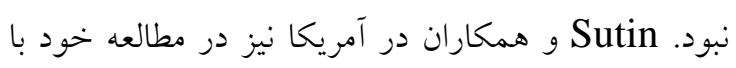

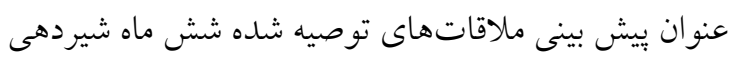
بر اساس توصيه WHO توسط ويز كى هاى شخصيتى بيان

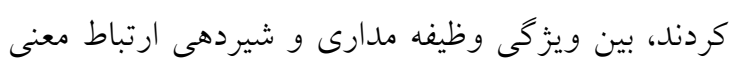

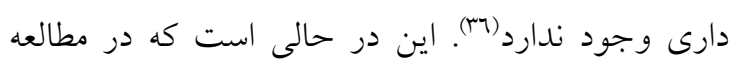

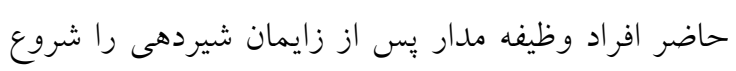
كرده و تا شش ماهكى ادامه دادند. اين اختلاف مى تواند

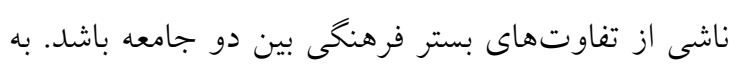

بحث و نتيجه كيرى نتايج يافتهها در مطالعه حاضر حاكى از آن بود بود كه از ميان

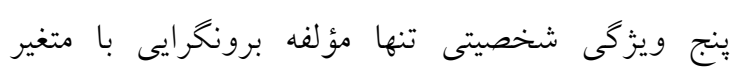

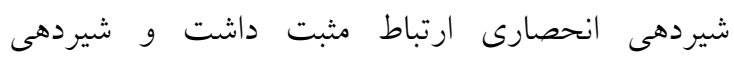

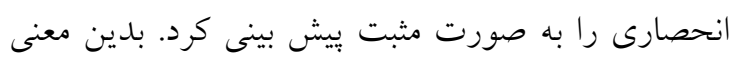

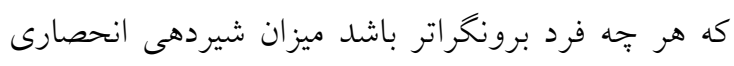

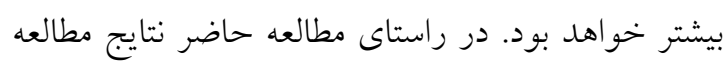

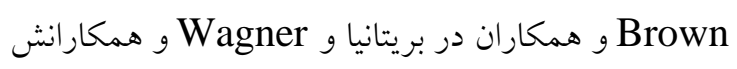

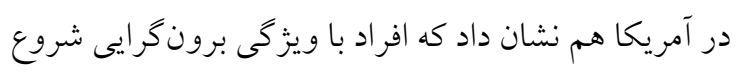
به شيردهى كرده و براى مدت طولانى ترى به شيردهى ادامه دئه

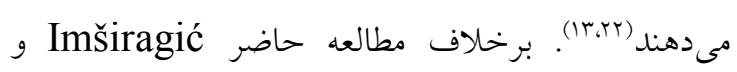
همكاران در كرواسى بين ويزگ كىهاى شخصيتى برون

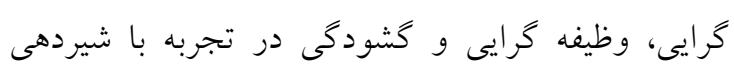

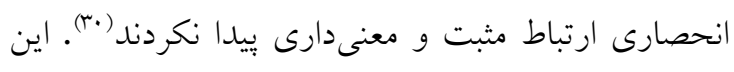
اختلاف مىتواند به دليل تفاوت در حجم نمونه و بستر فرهنكى متفاوت دو جامعه باشد.

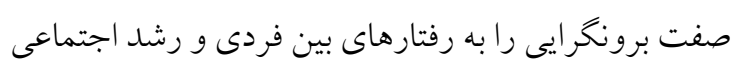

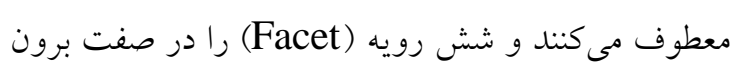

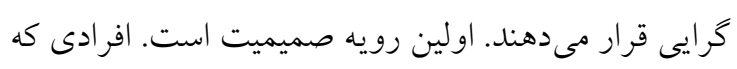

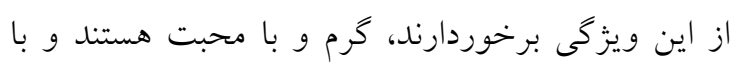
ديغران به راحتى دلبستخى نزديك ايجاد مئى كنند (r.).

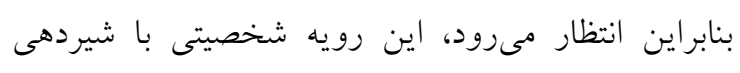

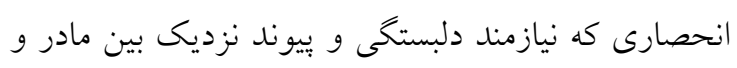

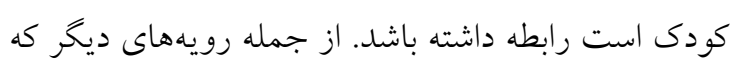

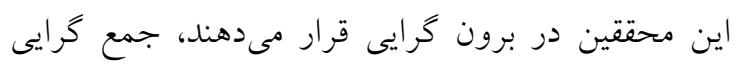

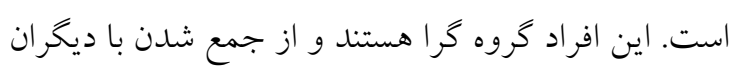
لذت مى برند و احساس شادى بيشترى مى كنند (rr-1").

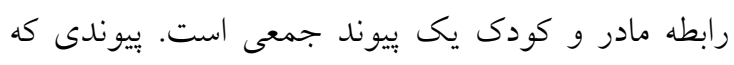

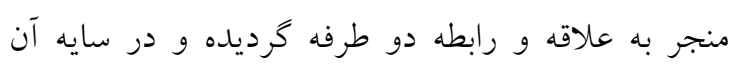

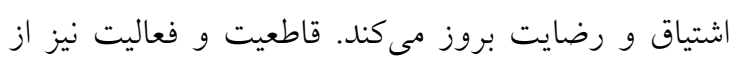
جمله رويههايى است كه اين محققين در صفت برونغرايى

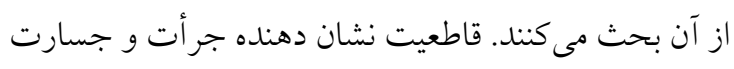

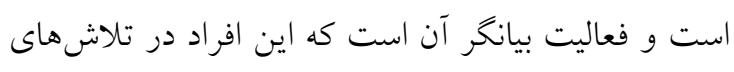
خود قدرت و نيروى بيشترى صرف مى كنند و در تداوم 
رابطه اين ويزگى هاى شخصيتى و شيردهى انحصارى را

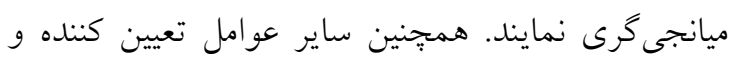

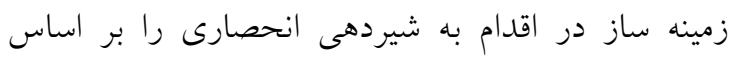
مطالعات كيفى كشف نمايند.

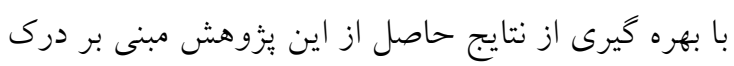

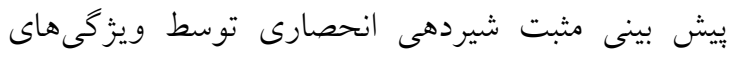

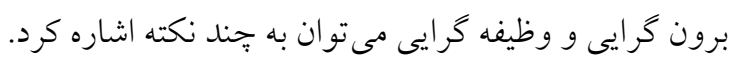

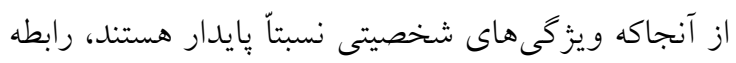

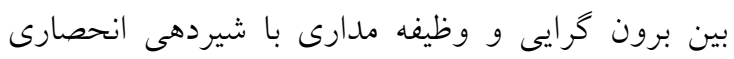

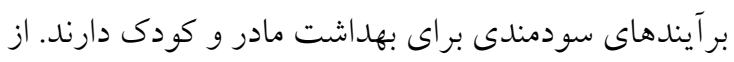

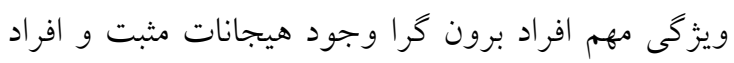

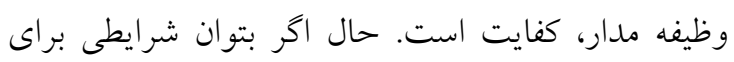

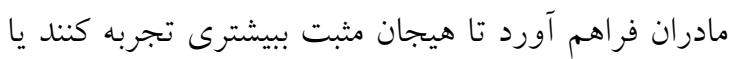
احساس كفايت و شايستخى بيشترى داشته باشند، مىتوان

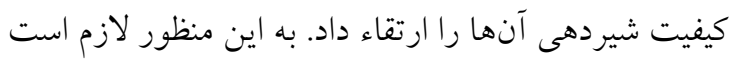

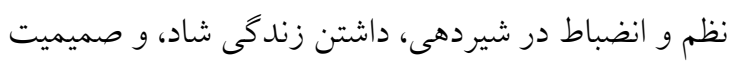

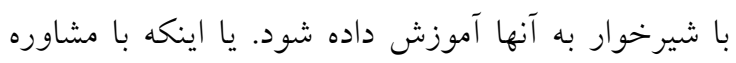

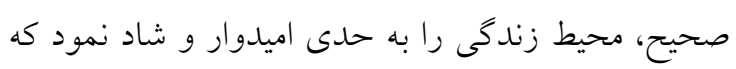

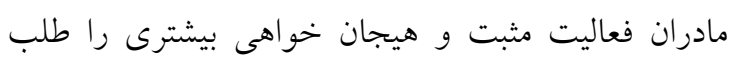

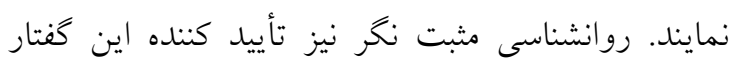

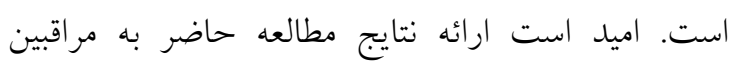
بهداشتى منجر به تشويق و حمايت بيشتر زنان در زمينه شيردهى انحصارى و ارائه مشاوره شيردهى ايمن در مراكز

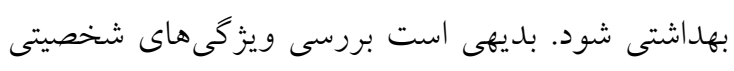

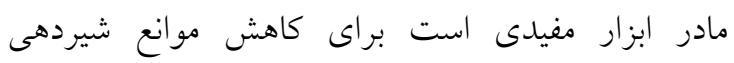

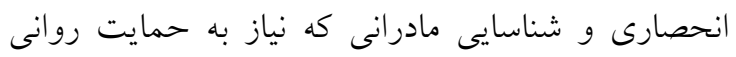

$$
\text { بيشترى دارند. - مئد }
$$

تعارض منافع:محققين بدينوسيله اظهار مىدارند كه در انجام اين يزوهش هيج گونه تعارض منافعى نداشتهاند.

\section{تقدير و تشكر}

اين مقاله بخشى از بايان نامه دانشجوى كارشناسى ارشد

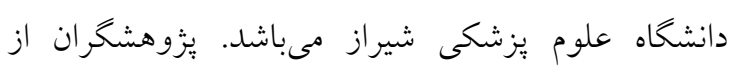

طوريكه در جامعه ايرانى مادران، شيردهى نوزاد را به عنوان يكى تكليف و وظيفه قلمداد مى كنند. ليكن در جوامع ديخر ممكن است اين موضوع به عنوان يكى وظيفه تلقى نشود. رويههاى كفايت، نظم و ترتيب، تلاش براى موفقيت،

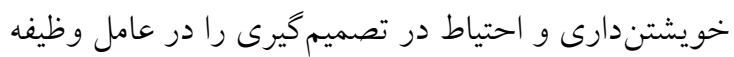

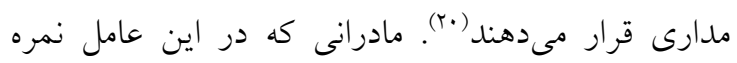
بالايى بدست مى آورند، احساس كفايت، قابليت و مؤثر بودن در سلامت نوزاد خود با شيردهى به وى دارند (rVV).

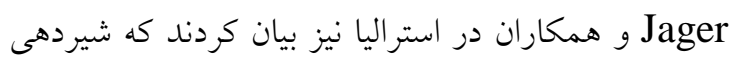

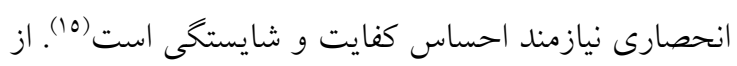
سوى ديخر شيردهى انحصارى نيازمند نظم و ترتيب است.

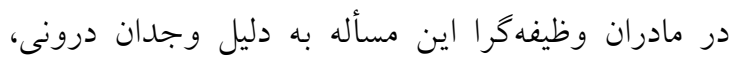
راهنمايى ها و دستور العمل هاى شيردهى منظم، جدى كرى كرفته

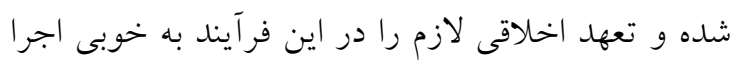

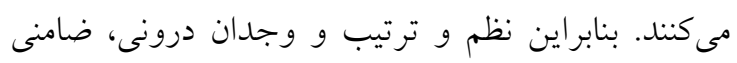

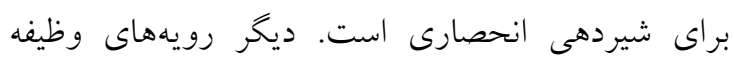

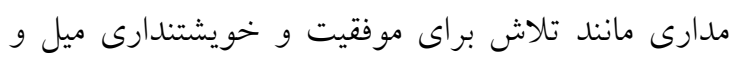

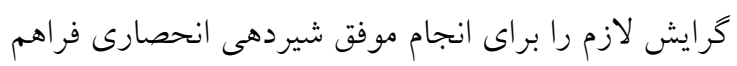

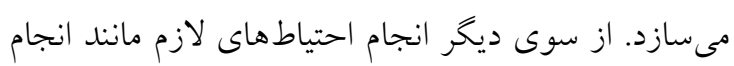

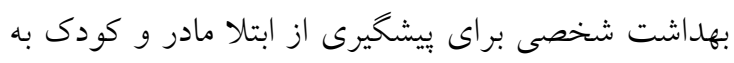

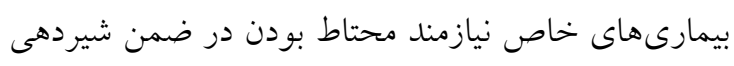

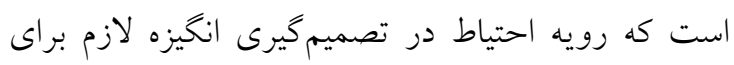

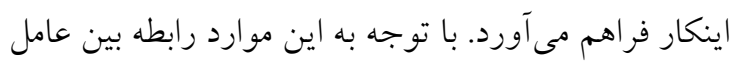

وظيفه مدارى و شيردهى انحصارى قابل توضيح است.

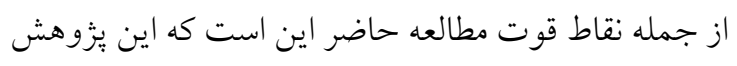

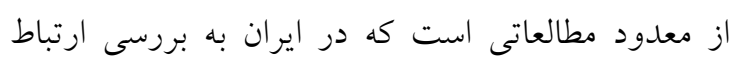

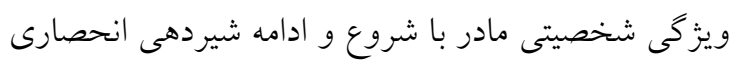

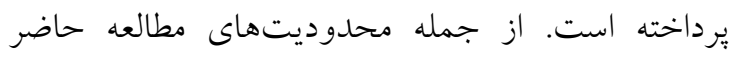
كمبود نمونههاى شركت كننده در زمان محدود جمع آورى آنس

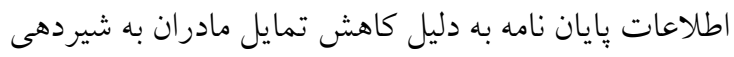

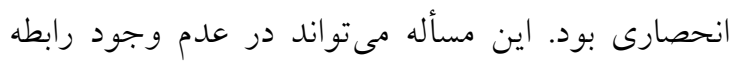

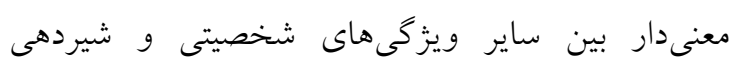

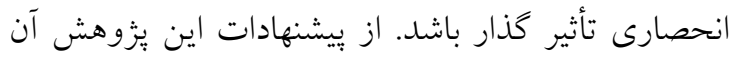
است كه محققين به متغيرهايى توجه نمايند كه مىتواند 
ياس مشاركت در اين طرح تحقيقاتى صميمانه قدردانى مى

كنיد.

$$
\text { مسئولين دانشگاه علوم يزشكى شيراز و كاركنان مراكز درمانى و مادران داراى شيرخوار } 7 \text { تا بال ماه به }
$$

\section{References}

1. Organization WH. Breastfeeding Internet: World Health Organization; 2018. Available from: https://www.who.int/news-room/facts-in-pictures/detail/breastfeeding.

2. Rollins NC, Bhandari N, Hajeebhoy N, Horton S, Lutter CK, Martines JC, Piwoz EG, Richter LM, Victora CG, Group TL. Why invest, and what it will take to improve breastfeeding practices?. The lancet. 2016;387(10017):491-504.

3. Lamberti LM, Walker CL, Noiman A, Victora C, Black RE. Breastfeeding and the risk for diarrhea morbidity and mortality. BMC public health. 2011;11(3):S15.

4. Boccolini CS, Carvalho ML, Oliveira MI, Boccolini PD. Breastfeeding can prevent hospitalization for pneumonia among children under 1 year old. Jornal de pediatria. 2011;87:399-404.

5. Binns C, Lee M, Low WY. The long-term public health benefits of breastfeeding. Asia Pacific Journal of Public Health. 2016;28(1):7-14.

6. Chowdhury R, Sinha B, Sankar MJ, Taneja S, Bhandari N, Rollins N, Bahl R, Martines J. Breastfeeding and maternal health outcomes: a systematic review and meta-analysis. Acta paediatrica. 2015;104:96-113.

7. Aune D, Norat T, Romundstad P, Vatten LJ. Breastfeeding and the maternal risk of type 2 diabetes: A systematic review and dose-response meta-analysis of cohort studies. Nutrition, Metabolism and Cardiovascular Diseases. 2014;24(2):107-15.

8. González-Jiménez E, García PA, Aguilar MJ, Padilla CA, Álvarez J. Breastfeeding and the prevention of breast cancer: a retrospective review of clinical histories. J Clin Nurs. 2014;23(1718):2397-403.

9. Luan NN, Wu QJ, Gong TT, Vogtmann E, Wang YL, Lin B. Breastfeeding and ovarian cancer risk: a meta-analysis of epidemiologic studies. Am J Clinl Nutr. 2013;98(4):1020-31.

10. World Health Organization U. Global Nutrition Targets 2025: Breastfeeding policy brief 2017. Available from: https://www.who.int/nutrition/publications/globaltargets2025_policybrief breastfeeding/en/.

11. UNICEF. Improving breastfeeding, complementary foods and feeding practices 2018. Available from: https://www.unicef.org/nutrition/index_breastfeeding.html.

12. Victora CG, Bahl R, Barros AJ, França GV, Horton S, Krasevec J, Murch S, Sankar MJ, Walker N, Rollins NC, Group TL. Breastfeeding in the 21st century: epidemiology, mechanisms, and lifelong effect. The Lancet. 2016;387(10017):475-90.

13. Brown A. Maternal trait personality and breastfeeding duration: the importance of confidence and social support. $J$ Adv Nurs. 2014;70(3):587-98.

14. Kelishadi R, Rashidian A, Jari M, Khosravi A, Khabiri R, Elahi E, Bahreynian M. national survey on the pattern of breastfeeding in Iranian infants: The IrMIDHS study. Medical journal of the Islamic Republic of Iran. 2016;30:425. [Persian]

15. de Jager E, Broadbent J, Fuller-Tyszkiewicz M, Nagle C, McPhie S, Skouteris H. A longitudinal study of the effect of psychosocial factors on exclusive breastfeeding duration. Midwifery. 2015;31(1):103-11.

16. Dennis CL, Faux S. Development and psychometric testing of the breastfeeding self-efficacy scale. Research in nursing \& health. 1999;22(5):399-409.

17. Costa PT, McCrae RR. Normal personality assessment in clinical practice: The NEO Personality Inventory. Psychological assessment. 1992;4(1):5.

18. Goldberg LR. The structure of phenotypic personality traits. Am psychol. 1993;48(1):26.

19. Yadollahi P, Khalaginia Z, Vedadhir A, Ariashekouh A, Taghizadeh Z, Khormaei F. The study of predicting role of personality traits in the perception of labor pain. Iranian journal of nursing and midwifery research. 2014;19(7 Suppl1):S97. [Persian]

20. McCrae RR, Costa PT. Validation of the five-factor model of personality across instruments and observers. J Person Social Psychol. 1987;52(1):81.

21. Friedman HS, Kern ML. Personality, well-being, and health. Ann Rev Psychol. 2014;65:719-42. 
22. Wagner CL, Wagner MT, Ebeling M, Chatman KG, Cohen M, Hulsey TC. The role of personality and other factors in a mother's decision to initiate breastfeeding. J Human Lactation. 2006;22(1):16-26.

23. Keller N, Medved V, Armano G. The influence of maternal personality and risk factors for impaired mother-infant bonding on breastfeeding duration. Breastfeeding Medicine. 2016;11(10):532-7.

24. Di Mattei VE, Carnelli L, Bernardi M, Jongerius C, Brombin C, Cugnata F, Ogliari A, Rinaldi S, Candiani M, Sarno L. Identification of socio-demographic and psychological factors affecting women's propensity to breastfeed: an Italian cohort. Front Psychol. 2016;7:1872.

25. Jalal M, Dolatian M, Mahmoodi Z, Aliyari R. The relationship between psychological factors and maternal social support to breastfeeding process. Electronic physician. 2017;9(1):3561-9.

26. Tashakori A, Behbahani AZ, Irani RD. Comparison of prevalence of postpartum depression symptoms between breastfeeding mothers and non-breastfeeding mothers. Iranian journal of psychiatry. 2012;7(2):61-5. [Persian]

27. Harrington D. Confirmatory factor analysis. Oxford university press; 2009.

28. Alami A, Moshki M, Alimardani A. Development and validation of theory of planned behavior questionnaire for exclusive breastfeeding. Journal of Neyshabur University of Medical Sciences. 2014;2. [Persian]

29. Khormaee F, Farmani A. Concluded that the Short form of Goldberg's 50-Item Personality Scale Is a Self-Report Instrument that Is Applied In Research Works and Has Good Validity And Reliability in Iranian Population. Quarterly Journal of Psychological Methods and Models. 2014;4(16):29-39. [Persian]

30. Srkalović Imširagić A, Begić D, Sarajlić Vuković I, Rojnić Palavra I, Orban M. Predictors of Exclusive Breastfeeding 6-9 Weeks after Delivery: A Prospective Cohort Study Public Mental Health Perspective. Psychiatria Danubina. 2016;28(4):395-403.

31. Goldberg LR. The development of markers for the Big-Five factor structure. Psychological assessment. 1992;4(1):26.

32. Zubaran C, Foresti K. The correlation between breastfeeding self-efficacy and maternal postpartum depression in southern Brazil. Sex Reprod Health care. 2013;4(1):9-15.

33. Grodin EN, White TL. The neuroanatomical delineation of agentic and affiliative extraversion. Cognitive, Affect Behav Neurosci. 2015;15(2):321-34.

34. T Verbeek T, L Quittner L, P de Cock P, de Groot N, Bockting C, Burger H. Personality Traits Predict Meeting the WHO Recommendation of 6 Months' Breastfeeding. Advances in Neonatal Care. 2018;19(2): 118-126.

35. Maliszewska KM, Bidzan M, Świątkowska-Freund M, Preis K. Socio-demographic and psychological determinants of exclusive breastfeeding after six months postpartum - a Polish casecohort study. Ginekologia polska. 2018;89(3):153-9.

36. Sutin AR, Stephan Y, Terracciano A. Breastfeeding and adult personality. Europ J Person. 2016;30(5):484-91.

37. Bogg T, Roberts BW. The case for conscientiousness: Evidence and implications for a personality trait marker of health and longevity. Ann Behav Medic. 2013;45(3):278-88. 